\title{
La gestión municipal de Cádiz durante la Segunda República Española y la Guerra Civil Española: las actuaciones del Alcalde republicano Manuel de la Pinta y el alcalde franquista Juan de Dios Molina (1932-1940)
}

\author{
Rafael Ravina Ripoll ${ }^{1}$ \\ José Joaquín Rodríguez Moreno²
}

Recibido: 20 de abril de 2014 - Aceptado: 25 de octubre de 2014

\begin{abstract}
Resumen
Las biografías están volviendo a ser utilizadas actualmente como herramientas historiográficas para el estudio del pasado. A través del estudio de las biografías, ideología y actuaciones de un alcalde democrático y otro franquista de Cádiz, descubriremos cómo el gobierno público local se vio influido más por la ideología que por los proyectos políticos de cada uno de ellos.

Palabras clave:Segunda República Española, Guerra Civil Española, Historia local, Cádiz.
\end{abstract}

Cadiz city management during the Second Spanish Republic and the Spanish Civil War: actions by the Republican Mayor Manuel de la Pinta and francoist Mayor Juan de Dios Molina (1932-1940)

\begin{abstract}
Biographies are currently used as historiographical tools for studying the past. Through the study of biographies, ideology and actions of a democratic mayor and a Francoist mayor from Cadiz we will discover how the local public administration was influenced more by ideology than by their own political projects.
\end{abstract}

Keywords: Second Spanish Republic, Spanish Civil War, local history, Cadiz.

Español. Profesor del Departamento de Organización de Empresas, Universidad de Cádiz, España. E-Mail: rafael.ravina@uca.es

2 Español. Doctor en Historia, Universidad de Cádiz, España. Profesor del Programa de Estudios Hispanolusos Northwest-Cádiz de la University of Washington. E-mail: tebeoteca@uca.es 


\title{
A gestão municipal de cádiz durante a Segunda República Espanhola e a Guerra Civil Espanhola: as ações do prefeito republicano Manuel de La Pinta e o prefeito Franquista Juan de Deus Molina (1932-1940)
}

\begin{abstract}
Resumo
As biografias estão retornando para serem utilizadas atualmente como ferramentas historiográficas para o estudo do passado. Através do estudo das biografias, ideologia e ações de um prefeito democrático e outro franquista de Cádiz, vamos descobrir como o governo público local viu-se mais influenciado pela ideologia do que os projetos políticos de cada um deles.
\end{abstract}

Palavras-chave: Segunda República espanhola, Guerra Civil espanhola, história local, Cádiz

Durante la última década se ha producido en España un renovado interés por los estudios relacionados con la breve experiencia democrática que supuso la Segunda República (1931-1936), la Guerra Civil provocada por la sublevación militar del ala dura del ejército apoyada por sectores civiles ultracatólicos y fascistas (1936-1939), y los primeros años de la dictadura del general Francisco Franco, periodo habitualmente denominado Franquismo (1939-1975). Este resurgimiento del tema, también conocido como Recuperación de la Memoria Histórica, más que estudiar las grandes batallas y el devenir político de los bandos, se ha centrado en analizar facetas específicas como la represión, la corrupción política o el día a día de la población. ${ }^{3}$ No obstante, el estudio de personajes concretos ha quedado prácticamente en el olvido, ${ }^{4}$ en buena medida porque los acontecimientos que sucedieron no pueden adjudicarse únicamente a la actuación de una persona o un reducido grupo de individuos, sino que fueron causados por una serie de sucesos tanto internos como externos que en ocasiones se remontan hasta finales del siglo XIX. ${ }^{5}$

3 A nivel español hay que señalar estudios como la represión ejercida por las fuerzas sublevadas en su avance por el sur de España (Espinosa Maestre, 2003) o en todo el país (Preston, 2011), la depuración de los maestros de escuela en las zonas ocupadas por los militares rebeldes (Pettennghi Lachambre, 2005) o la perpetuación de los valores franquistas a través de las lecturas infantiles (Rodríguez Moreno, 2013). En la localidad de Cádiz, que es en la que vamos a centrar este trabajo, destacan el estudio de la represión política en la capital (Domínguez Pérez, 2005) y en las poblaciones de la provincia (Romero Romero, 2009), además de estudios sobre la vida cotidiana y las carencias de la posguerra (Moreno Tello, 2006).

$4 \quad$ Una honrosa excepción a este olvido de las biografías es el trabajo de Fernando Romero Romero sobre Fernando Zamacola, un destacado miembro de la agrupación fascista Falange Española. En su trabajo (2011) se desmonta minuciosamente el mito heroico que la dictadura había montado alrededor del personaje tras su muerte en combate y se prueban los crímenes de guerra que cometió durante la Guerra Civil.

5 Los historiadores Julián Casanova y Carlos Gil Andrés señalan que elementos como el ascenso de las opciones republicanas, el agotamiento del sistema político dirigido por las oligarquías, 
En el presente trabajo queremos romper con esta línea y analizar la biografía de dos alcaldes de la ciudad de Cádiz, el republicano Manuel de la Pinta Leal (1905-1936) y el franquista Juan de Dios Molina Arroquia (1897-1979). Sin embargo, el profesor Octavio Ruiz Manjón-Cabeza ya señaló en su día que este tipo de estudios no puede quedarse en lo puramente estadístico, sino que "especialmente importante será, en este sentido, todo lo que permita relacionar la evolución de los cargos políticos locales con los condicionamientos sociales y económicos de las diferentes provincias, así como [con] los datos personales (...)" (1979). Por ello, nuestro interés va a estar en ver cómo dos personas que partían de bases similares (ambos eran miembros de la clase media que ejercían profesiones liberales) y llegaron a la alcaldía con las mismas preocupaciones, tomaron en la práctica decisiones que dejaron ver unos planteamientos ideológicos y vitales distintos. El primer objetivo de nuestro trabajo es, por lo tanto, ver qué problemas afrontaba la ciudad de Cádiz en el periodo estudiado. En segundo lugar, nos planteamos conocer mejor la trayectoria vital e ideológica de ambos alcaldes, con el objetivo de comprender mejor su forma de proceder. Finalmente, veremos sus principales actuaciones y concluiremos qué factores les movieron a ello y a qué sectores de la ciudad favorecieron con sus medidas.

\section{Método y bases téoricas}

Tras un largo periodo en el que las biografías han estado marginadas en la historiografía española, siendo consideradas generalmente como anecdóticas o puramente hagiográficas, se ha producido un nuevo interés a consecuencia de la renovación metodológica que se viene produciendo en dicho campo desde los años noventa. Los trabajos que se realizan han cambiado, por lo tanto, su percepción del personaje relevante, y ya no se le considera como el motor único de los hechos históricos, sino como un individuo incrustado en un contexto histórico y catapultado a una posición relevante que, fruto de su educación, creencias y circunstancias personales, gestiona de una u otra manera las situaciones que enfrenta ${ }^{6}$. Lejos de ser esta una tendencia puramente española, este cambio viene amparado por prestigiosos estudios anglosajones, como los trabajos de Paula R. Backscheider (1999) y James

el aumento de la implicación de las masas en la vida política y la respuesta reaccionaria del clero y los militares ante los cambios sociopolíticos comenzaron a producirse en la última década del siglo XIX, intensificándose a partir del desastre militar que supuso la pérdida de Cuba, Puerto Rico y Filipinas en 1898 (2009).

6 A tal respecto encontramos trabajos enfocados en un solo personaje, como el estudio sobre el presidente español Antonio Maura (Sevilla Andrés, 2010) o el último presidente de la Segunda República (López Aguilar, 2013); pero también encontramos trabajos centrados en grupos amplios, como el análisis de los parlamentarios españoles a principios del siglo XIX (Urquijo Goitía, 2010) o de los socialistas (Barruso Barés, 2010). 
Walter (2006), a los que se suman los esfuerzos por recopilar biografías y hacerlas accesibles a través de la Red del British Institute of Biography, vinculado a la Royal Holloway University of London?

Pero la realización de este trabajo en concreto tiene algunas particularidades, pues en lugar de centrarnos en un personaje vamos a comparar las biografías de dos individuos. Para ello hemos realizado una recopilación de fuentes no muy diferente a la requerida para otros estudios biográficos, consultando diversos archivos y hemerotecas tanto locales como nacionales. En el caso de Manuel de la Pinta también nos hemos ayudado de una breve biografía política realizada hace pocos años (Benítez, Moreno y Núñez, 2011) que, eso sí, hemos cotejado y complementado con otras fuentes; para la biografía de Juan de Dios Molina hemos utilizado como base algunos trabajos que habíamos realizado previamente, si bien han sido ampliados en gran medida con el trabajo de archivo. Para el contexto histórico también hemos recurrido a diversas investigaciones recientes, seleccionando entre el amplio abanico de estudios disponibles aquellos realizados por autores con una larga trayectoria investigadora o avalados por el sello de universidades o editoriales especializadas.

Una vez reunida la información, hemos creído necesario dividir el análisis histórico en cuatro partes. En primer lugar, un contexto histórico general para entender la situación de Cádiz, su problemática y la forma en que la Guerra Civil afecta a la ciudad. En segundo lugar, exponemos el contexto personal de los dos alcaldes para intentar comprender mejor su personalidad y orientación política, contrastando ambas para comprender las similitudes y las diferencias entre ellos. Seguidamente analizamos el clima político en el que ambos llegan al poder. Finalmente, comparamos las actuaciones de uno y otro, viendo cómo a idénticos problemas reaccionaron de maneras distintas. En las conclusiones ahondaremos en estas actuaciones e intentaremos interpretarlas para comprender qué factores les inducen a tomar decisiones en ocasiones opuestas para solventar un mismo problema.

\section{El contexto histórico: El Cádiz de los años treinta}

La ciudad de Cádiz se encuentra situada en el sur de la Península Ibérica, de cara al Océano Atlántico, controlando el acceso a una bahía que durante siglos sirvió de puerto natural para las embarcaciones. La vocación marítima de la ciudad alcanzó su punto álgido en los siglos XVII y XVIII, cuando obtuvo el monopolio del comercio con las colonias de América y Filipinas (Bustos

El sitio web del British Institute of Biography es http://www.biography.org.uk 
Rodríguez, 2005), y aunque las independencias americanas redujeron la importancia de la localidad, siguió conservando un valor económico y estratégico durante el siglo XIX (Ramos Santana, 1992). Sin embargo, la independencia de Cuba, Puerto Rico y Filipinas tras la guerra hispano-estadounidense (1898) supuso un duro golpe económico para la ciudad y su industria (principalmente sus astilleros), ejecutando las autoridades a partir de ese momento diversos programas de obras públicas que se prolongaron hasta finales de los años veinte y que, a modo de un bálsamo que aliviara el dolor sin curar la enfermedad, evitaron las protestas sociales sin por ello impedir la decadencia económica gaditana (Millán Chivite, 1993).

A principios de los años treinta, finalizados los programas de obras públicas y con unos astilleros al borde de la quiebra, Cádiz sufre con aún más dureza que el resto del país la crisis económica mundial iniciada en 1929 (Gutiérrez Molina, 1994). De hecho, al analizar la estructura empresarial de la ciudad se hace patente la falta de tejido industrial, que no supone más que el 7,3\% en el centro de la ciudad y un tímido $2,2 \%$ en la periferia, justamente donde existe más espacio para la localización industrial (AHMC). El destartalado motor económico de Cádiz lo componen, por lo tanto, negocios comerciales y hosteleros, que representan respectivamente el 53,3\% y el 33,7\% de las empresas locales (AHMC). Aunque Mirás Araujo ha comprobado a partir del caso de A Coruña que el sector terciario puede ser durante esta época soporte de la economía de una ciudad marítima (2004), la extrema debilidad del entramado industrial y la decadencia del muelle impiden que los servicios tengan la misma fuerza que en otras ciudades portuarias. Además, las obras públicas posiblemente hayan acostumbrado a las élites económicas locales a invertir en proyectos de nulo riesgo y beneficios seguros, explicando así el escaso interés por inversiones privadas que conlleven cierto riesgo.

Pero la ciudad, considerada de tamaño medio en los censos de la época (Dirección General de Estadística, 1943), no pierde población a pesar de la crisis; de hecho, a principios de la década de los treinta cuenta con 75.769 habitantes, siendo por lo tanto la mayor urbe de la provincia, seguida de cerca por Jerez de la Frontera con 72.055 vecinos y, a mayor distancia, por La Línea de la Concepción con 35.371 habitantes (Instituto Geográfico, Catastral y de Estadística, 1932). No cabe duda de que la desaparición de las crisis de subsistencia ayudaron al aumento de la población incluso en época de inestabilidad económica (Casanova y Gil Andrés, 2009), pero eso no significa que las condiciones de vida sean óptimas, señalando Gutiérrez Molina la pobreza de la dieta de las clases populares, el hacinamiento provocado por la escasez de vivienda y la consecuente insalubridad de unos barrios ya de por sí mal habilitados para cumplir unos mínimos higiénico-sanitarios (1994). Esta problemática va a hacer que los diversos gobiernos municipales del primer tercio del siglo se planteen urbanizar el área de extramuros de la 
ciudad, si bien a mediados de los años treinta encontramos que el centro urbano amurallado sigue conteniendo el $94,2 \%$ de las viviendas y el $93,4 \%$ de la estructura empresarial gaditana (AHMC). ${ }^{8}$

El hecho de que la población no se reduzca a pesar de la decadencia económica de la ciudad puede deberse a varios factores. Por un lado, los planes de obras públicas al parecer tuvieron un efecto positivo en la población, que no acusó con tanta severidad durante los años diez ni veinte la pérdida de importancia del puerto ni la cada vez mayor crisis del sector naviero. Por otro lado, al ser la capital de la provincia, Cádiz es sede de muchos de los servicios y administraciones locales, concentrando a finales de la década al $46,1 \%$ de hombres con profesiones liberales de toda la provincia, cifra que se dispara hasta el 97,3\% en el caso de las mujeres con profesiones liberales (Dirección General de Estadística, 1943). Posiblemente esta numerosa población de funcionarios y profesionales, sumada al reciente pasado comercial de la localidad, sea lo que explique uno de sus fenómenos más extraordinarios: el mayor índice de instrucción de sus habitantes en comparación con otras ciudades andaluzas. En 1930 la cifra de analfabetismo es de un $26,45 \%$ ( $23,1 \%$ en los hombres y un $29,8 \%$ en las mujeres) frente al $45,6 \%$ de Jerez de la Frontera y al 50,7\% de la Línea de la Concepción; de hecho, esta cifra es inferior a la de las grandes ciudades andaluzas, como el 27,4\% de Sevilla o el 40,5\% de Málaga (Instituto Geográfico, Catastral y de Estadística, 1932).

Más cultivada y con un importante sector de funcionarios y profesionales de clase media, no es de extrañar que la ciudad de Cádiz acoja con grandes esperanzas la proclamación de la Segunda República tras el hundimiento de los partidos monárquicos en las elecciones municipales de abril de 1931, cuyo mejor representante es el alcalde Manuel de la Pinta y su proyecto para mejorar la situación de la ciudad (Millán Chivite, 1993). No obstante, el alzamiento del ejército colonial de Marruecos el 17 de julio de 1936 y el inicio de la Guerra Civil suponen un final dramático para la primera experiencia totalmente democrática del siglo XX (Caro Cancela, 1987). Cádiz queda en cuestión de horas emplazada en la retaguardia del bando sublevado sin apenas sufrir daños materiales (Espinosa Maestre, 2005), si bien la dura represión y las ejecuciones no ayudan a mejorar la situación de la ciudad (Domínguez

\footnotetext{
Obviamente, la Guerra Civil va a hacer que la media de vida oscile, reduciéndose en 1937 hasta los cuarenta y siete años y diez meses (Saínz Otero, 2007). Y es que, aunque Cádiz no sufre los efectos de bombardeos severos ni bloqueos graves, la contienda supuso un empeoramiento de las condiciones de vida, a lo que hay que sumar las ejecuciones políticas llevadas a cabo por el bando sublevado, que entre 1936 y 1945 suman 698 asesinatos (Domínguez Pérez, 2005). En general, la mortalidad aumenta durante la contienda en un 11\% (Instituto Nacional de Estadística, 1957), aunque esta cifra puede ser mayor, pues algunos prisioneros políticos son asesinados sin que se registre su muerte, mientras que otros son ejecutados fuera de la localidad (Domínguez Pérez, 2005).
} 
Pérez, 2005), que hasta finales de los años cuarenta sufrirá por la escasez de alimentos y el aislamiento internacional producidos por la contienda (Moreno Tello, 2006). Es en ese contexto bélico en el que aparece la figura de Juan de Dios Molina, quien guarda numerosos paralelismos con De la Pinta.

\section{El contexto personal: Trayectoria vital de Manuel De la Pinta Leal y Juan de Dios Molina Arroquia}

En una época en la que los alcaldes suelen ser personas pertenecientes a las oligarquías locales o que habían hecho carrera dentro de los aparatos políticos de la monarquía y la dictadura, tanto Manuel de la Pinta como Juan de Dios Molina llaman la atención por no pertenecer a familias de renombre, encuadrándose ellos mismos dentro de las filas de la clase media.

En el caso de De la Pinta Leal, su padre era comandante de carabineros (Sección $1^{\text {a }}$, legajo P238. AGMS) y su madre procedía de una familia acomodada (Benítez, et al., 2011). Originario de Málaga, el joven De la Pinta acudió a la cercana ciudad de Cádiz a estudiar Medicina a mediados de los años veinte, donde destacó por sus sobresalientes notas, entre las que se cuentan seis matrículas de honor (Expediente de Manuel de la Pinta Leal. AUCA). Tan pronto como finalizó sus estudios en 1928, con solo 23 años de edad, superó el examen de oposición pública de Inspector Municipal de Sanidad al mismo tiempo que iniciaba su carrera como profesor ayudante en la Facultad de Medicina de Cádiz (Benítez et al., 2011), quedándose de este modo afincado en la ciudad.

La familia de Molina tenía unos orígenes similares, siendo el padre de éste funcionario en la administración pública (Hoja de servicio de Mariano Molina Arauco, AMH), perteneciendo también su madre a una familia acomodada (Mesa Fernández, 1996). Nacido en Jódar, un pueblo de la provincia de Jaén, el joven Molina Arroquia realizó sus estudios universitarios de Ingeniería Industrial en Madrid entre 1921 y 1923, obteniendo buenas calificaciones (Expediente de Juan de Dios Molina Arroquia, AGUPM). Durante esta etapa como estudiante se alojó en la Residencia de Estudiantes de Madrid ${ }^{9}$ (AHFM),

Fundada en 1910, la Residencia bebía de los principios de la Institución Libre de Enseñanza de Francisco Giner de los Ríos (1839-1915), que apostaba por la formación amplia y creativa del estudiante. Fue el primer centro cultural creado en España, y gozó de una activa vida intelectual durante el periodo de entre guerras, apostando por la formación complementaria de los estudiantes universitarios, y por ella pasaron algunas de las figuras más importantes de la cultura española del siglo XX, como los poetas Federico García Lorca, Juan Ramón Jiménez y Rafael Alberti, el pintor Salvador Dalí, el cineasta Luis Buñuel y el científico Severo Ochoa, entre muchos otros. Además, fue un foro de debate al que acudieron figuras europeas como Albert Einstein, Marie Curie, John M. Keynes o Le Corbusier (Sáenz de la Calzada, 1986). 
donde disfrutó de un ambiente de estudio más democrático y liberal de lo acostumbrado en la España de la época (Ravina Ripoll, 2010). Su llegada a Cádiz tuvo lugar en 1928, cuando tomó una plaza como ingeniero industrial en la fábrica de tabacos de la ciudad (AHFM). Sin embargo, permaneció poco tiempo en dicho puesto, ya que a finales de ese mismo año el alcalde y oligarca local Ramón de Carranza ${ }^{10}$ lo nombró director de los Servicios Municipalizados de Electricidad, comenzando a ejercer el 1 de enero de 1929 (Hoja de servicio de Juan de Dios Molina Arroquia, AHAC).

Quizá la diferencia más notable entre ambos personajes fue la manera en que desarrollaron sus vidas familiares y profesionales. Molina se casó mediante el rito católico tradicional con una mujer de buena familia venida a menos, Rafaela Rubín de Ceballos Gómez Sellés (AHFM). Por el contrario, De la Pinta tuvo diversos choques con su propia familia debido a su costumbre de pasar consulta médica a los más necesitados sin cobrarles, pero también por convivir sin estar casado con su pareja, María Alba Medina (Benítez et al., 2011). Por ello, a pesar de las numerosas coincidencias en sus orígenes, ya podemos ver una clara diferencia en sus formas de vida, ya que mientras uno vive acorde a las expectativas sociales tradicionales, el otro rompe con ellas incluso cuando eso le supone problemas económicos y discusiones familiares.

\section{El contexto político: La llegada al poder de los alcaldes}

La implicación política de estos dos personajes queda clara en momentos clave, siendo sus actuaciones tan decisivas que les van a valer el firme apoyo de los círculos políticos en los que se mueven, catapultándoles al puesto de alcalde.

Manuel de la Pinta Leal deja ver sus tendencias políticas pocas semanas antes de las elecciones municipales de abril de 1931, cuando durante los estertores finales de la monarquía funda las Juventudes Republicanas de Cádiz (Benítez et al., 2011). A esto se suma su activa participación en dichas elecciones, denunciando las prácticas corruptas de la oligarquía de la ciudad encabezada por el alcalde Ramón de Carranza (Caro Cancela, 1987). Sus denuncias ayudan a poner fin a la etapa de Carranza como alcalde, pasando el poder a un nuevo consistorio de mayoría republicana, en el que De la Pinta se estrena como concejal por el Partido Republicano Autónomo. Durante ese

10 Ramón de Carranza y Fernández de la Reguera (1863-1937) fue un militar español de origen gallego, si bien se trasladó a la ciudad de Cádiz, siendo un destacado miembro de la oligarquía de esta ciudad. Durante la monarquía jugó un importante papel político como diputado, senador y alcalde de Cádiz (1927-1931), siendo un ferviente opositor a la Segunda República y apoyando abiertamente la sublevación militar, lo que le valió ser nombrado nuevamente como alcalde (1936). Su biografía fue analizada por el historiador Joaquín Piñeiro Blanca (1998). 
mismo año, el joven médico participa muy activamente en la Delegación de Beneficencia y Sanidad por un lado, y en la Delegación de Mercados, Mataderos y Abastos por otro (Benítez et al., 2011).

Su actuación crítica durante las elecciones y su dinamismo en las comisiones de las que forma parte lo convierten en el sucesor ideal del alcalde Enrique Álvarez López en el verano de 1932, que abandona su puesto para dedicarse por entero a su cargo como diputado (Acta Capitular libro 10.408, 10 de junio de 1932. AHMC). Esta primera etapa con De la Pinta al frente del municipio dura hasta octubre de 1934, cuando el nuevo gobierno central conservador (conformado por el Partido Republicano Radical y la Confederación Española de Derechas Autónomas) logra sustituir con diversas maniobras a las corporaciones municipales gobernadas por republicanos-socialistas por otras más afines a sus políticas (Millán Chivite, 1993). Habrá que esperar un año y medio para que De la Pinta, coincidiendo con la victoria en las elecciones generales de la coalición de partidos de izquierda y socialistas que se vino a llamar Frente Popular (Vilar, 1986), volviera a ser nombrado alcalde el 20 de febrero de 1936 (Diario de Cádiz, 21 de febrero de 1936). En dicho puesto permanece hasta la sublevación militar del 18 de julio de 1936, siendo detenido y fusilado sin juicio por los militares rebeldes en el verano de ese mismo año (Benítez et al., 2011)11.

En lo referente a Juan de Dios Molina, éste no parece mostrar especial interés por la política durante los años de la Segunda República (AHFM). Sin embargo, cuando la ciudad de Cádiz queda a oscuras la madrugada del 18 de julio de 1936 como parte de la estrategia de los leales al gobierno republicano para ralentizar el avance de las fuerzas sublevadas, el ingeniero abandona el hogar familiar $y$, junto a algunos operarios, restablece el servicio eléctrico (Comisión del comportamiento del personal de los Servicios Municipales, 28 de julio de 1936. AHAC). La acción, que facilita así la actuación de las tropas rebeldes, le merece unos días después la felicitación de Ramón de Carranza, que ha vuelto a ocupar el puesto de alcalde bajo el patronazgo del régimen militar (Mora Figueroa, 1974) ${ }^{12}$.

11 Se da el hecho de que un capitán sublevado de la Guardia Civil solicitó por escrito el "honor" de acabar él mismo con la vida del alcalde: "Con alegría leo en la prensa de hoy que... ha sido detenido el canalla, bandido y sinverguenza (sic) del último alcalde Socialista de Cádiz Manuel de la Pinta Leal... ante sta (sic) alegría llamé por teléfono al Jefe de la Guardia Civil [para que] te hiciese presente el interés grande que tengo en fusilarlo... Por ser preciso mi servicio en Écija no he podido darme el gustazo de fusilar a los canallas de [mi localidad]" (Benítez et al., 2011:378). No obstante, De la Pinta Leal fue ejecutado tan rápidamente que cuando la carta llegó a su destinatario, el alcalde ya había sido asesinado.

12 El regreso a la vida pública de los oligarcas locales que habían detentado cargos públicos no fue algo excepcional de Cádiz, sino que se dio en más municipios españoles, como ha 
La imposibilidad de Ramón de Carranza de seguir al frente de la alcaldía unos meses después (en este caso a causa de una enfermedad que acabará con su vida) fuerza su renuncia como alcalde (Acta Capitular nº 30, 16 de julio de 1937. AHMC), eligiendo a Molina Arroquia como su sucesor, que se ve recompensado de esta manera por su lealtad durante el alzamiento militar (Ravina Ripoll, 2007). El cargo lo desempeña hasta que en 1940 presenta por sorpresa su dimisión, mostrando su disgusto con la vida política de la ciudad (que no con el régimen militar del general Francisco Franco) y retornando a su puesto como director de los Servicios Municipalizados de Electricidad (Ravina Ripoll, 2007), manteniéndose al frente de los mismos hasta su jubilación (Martínez Vargas, 1996).

De esta manera, sin haber sido ninguno de estos dos personajes la primera alternativa a la hora de dirigir el consistorio municipal, De la Pinta y Molina se convierten en alcaldes por una mezcla de casualidad, capacidad y lealtad al sistema político bajo el que ascienden.

\section{Objetivos y actuaciones municipales}

Apuntábamos al principio de este trabajo que la situación de la ciudad de Cádiz era muy difícil durante los años treinta, fruto del alto desempleo, la decadencia de la industria local, la falta de viviendas y las malas condiciones de los barrios populares. La crisis económica supone, además, una escasez de crédito que se hará aún más grave con la Guerra Civil (Ravina Ripoll, 2007). Tanto Manuel De la Pinta como Juan de Dios Molina van a intentan solventar, o al menos paliar, estas situaciones a través de las herramientas que el poder municipal les ofrece.

Manuel De la Pinta declara desde un primer momento su deseo de aliviar la difícil situación de la clase obrera y dar solución al acuciante problema de la escasez de viviendas. Para ello da preferencia a diversos proyectos heredados del ayuntamiento monárquico, principalmente las obras públicas, para dar empleo a la población (Diario La Información, 3 al 27-III-1936), y la creación de una zona industrial que atraiga nuevas fábricas a la localidad (Diario Acción Republicana, 9-VII-1932). Además, se constata una gran preocupación por la educación de las jóvenes generaciones, posiblemente por la convicción de que una juventud bien instruida podrá aspirar a mejores puestos de trabajo y participar mejor en un sistema democrático (Gutiérrez Molina, 1994). Por lo tanto, la construcción de colegios se vuelve una preocupación del ayuntamiento republicano, que en 1932 inicia una serie de trámites que son frenados tan pronto como se produce

estudiado Santiago de Pablo en su investigación sobre la continuidad y el cambio en las élites locales en la localidad vasca de Álava (1990). 
la victoria de la coalición del Partido Republicano Radical y la Confederación Española de Derechas Autónomas entre 1934 y 1936. Con todo, hubo ciertos avances, ya que antes de ser depuesto por el gobierno central de la alcaldía, De la Pinta logró asegurar los terrenos en la zona conocida como Campo del Sur para la construcción de una Escuela Normal y una Residencia de Estudiantes (Benítez et al., 2011). Una vez restituido como alcalde tras la victoria electoral del Frente Popular en 1936, De la Pinta intenta poner en marcha nuevas escuelas, pidiendo al gobierno central que le permita utilizar como escuelas las instalaciones que hasta aquel momento han alojado al seminario católico (Domínguez Pérez, 2005); esta medida se entiende no solamente como parte de un programa de mejora de la instrucción pública, sino como parte de una convicción anticlerical que, en palabras de Moral Roncal, busca acabar con la religión como un poder con gran influencia en la esfera pública "recluyendo (...) simbólicamente la religión al interior de las casas, al interior de la vida de cada ser humano" (2012). Por otro lado, en esta fase final de su mandato, De la Pinta también tiene que enfrentar la amenaza de los astilleros de cerrar sus puertas, lo que daría el golpe de gracia a la industria gaditana, de tal modo que el alcalde plantea al gobierno central la expropiación de éstos, que se acaba produciendo en el mes de mayo de 1936 (Gutiérrez Molina, 1996). Finalmente, el problema de la vivienda también se intenta paliar, si bien no con la construcción de nuevos inmuebles, pues el ayuntamiento no tiene recursos para ello, sino tomando medidas legales contra quienes alquilan viviendas que no cumplen las mínimas condiciones de habitabilidad (Domínguez Pérez, 2005). Todas estas medidas llevan a un claro descontento de la Iglesia y la oligarquía local, que se traduce en diversos incidentes e incluso en amenazas de muerte contra los miembros del ayuntamiento, sobre todo por parte del partido fascista español, la Falange Española (Benítez et al., 2011).

Tras la sublevación militar y el año que Ramón de Carranza pasa al frente del ayuntamiento, la llegada de Juan de Dios Molina a la alcaldía en 1937 es aclamada por la prensa (Diario La Información, 3-VIII-1937), lo cual no es de extrañar teniendo en cuenta que los periodistas que no han mostrado su apoyo a los militares han sido despedidos en el mejor de los casos, represaliados la mayoría de las veces y ejecutados en no pocas ocasiones (Moreno Tello, 2008). La prensa fascista, controlada por Falange Española, llega a alabar la figura del nuevo alcalde en contraposición a aquellos "tiempos ominosos en que el Ayuntamiento de la muy Noble, Muy Leal y Muy Heroica Ciudad de Cádiz, llegó a estar regido por un horda indocumentada, que entendió que la Administración del pueblo era dilapidar el patrimonio municipal repartiendo prebendas y llenando bolsillos" (Revista Águila, 3-VIII-1937); de esta supuesta corrupción no hay testimonio documental alguno, pero es de imaginar que los miembros de Falange no desean más que cimentar la figura del nuevo alcalde, que a diferencia de Carranza es un desconocido para la mayoría de la población. De hecho, Molina expresa su preocupación por los mismos problemas que 
el último alcalde republicano: la urbanización de la ciudad, la educación y la dramática situación de la clase trabajadora, si bien en su discurso no habla de creación de empleos ni de los derechos de los trabajadores, sino de acciones de "beneficencia" (Acta Capitular n³3, 2 de agosto de 1937. AHMC).

Para afrontar el problema de la vivienda, el consistorio municipal dirigido por Molina pone a la venta en subasta pública los terrenos propiedad del ayuntamiento que existen en la parte de extramuros de la ciudad. Ahora bien, golpeada por una crisis económica y una Guerra Civil, es obvio que las pujas van a ser escasas, beneficiando a una oligarquía gaditana acostumbrada a las inversiones seguras, que adquiere numerosos terrenos a un precio muy por debajo del valor del mercado (Legajo ${ }^{\circ} 1.998$, Expedientes de licencias de obras de 1939. AHMC). La medida viene acompañada del compromiso de participar en la urbanización del lugar (Legajo n 6.249, Expedientes del negociado de urbanización de extramuros, 1936-1940. AHMC), que al convertirse en viviendas de lujo o en bloques de apartamentos cercanos a la playa acabarán generando grandes beneficios a sus compradores. Cierto es que se construyen viviendas sociales, pero éstas no se levantan en las zonas frente a la playa que el ayuntamiento recién ha vendido a las élites locales, sino en las menos atractivas zonas de San Severiano y Puntales, siendo construcciones baratas que ni siquiera poseen agua corriente, y que son financiadas por la administración central (Legajo $n^{\circ}$ 5.881, Expedientes de licencias de obras durante 1936. AHMC). La inyección de dinero a las arcas municipales que supone la venta de terrenos se emplea para realizar obras públicas, que en ocasiones benefician a las clases trabajadoras, como la finalización de los colegios cuyas obras ya han comenzado durante la república (Legajo $n^{\circ} 3.311$, Colegios Particulares y Religiosos. AHMC), si bien la oligarquía, la Iglesia y la Falange Española son las principales beneficiarias de esta nueva ola de inversión local. Por ejemplo, se arreglan y acondicionan las zonas de la ciudad más frecuentadas por las clases pudientes, como el Paseo Marítimo (Legajo $n^{\circ}$ 5.111, Expedientes varios del Hotel Playa, 1931-1938. AHMC); se restaura el Balneario de la Palma para cederlo al grupo de juventudes de la Falange Española (Legajo n 5.885 , Certificaciones de obras municipales, 1934-1940. AHMC); y se procede al arreglo de diversas iglesias que pertenecen al obispado (Diario de Cádiz, 28-V-1938 y 25-VII-1938).

Cierto es que la educación liberal de Juan de Dios Molina se trasluce en algunos actos, si bien más simbólicos que prácticos. Por ejemplo, cuando el consistorio municipal vota cambiar el nombre de la escuela Hermenegildo Giner de los Ríos ${ }^{13}$ por el de Generalísimo Franco, el alcalde se abstiene en

13 Hermenegildo Giner de los Ríos (1847-1923) fue un pedagogo español que, junto a su hermano Franscisco, fue fundamental para el desarrollo de la Institución Libre de Enseñanza, que influiría enormemente en la Residencia de Estudiantes donde Juan de Dios Molina Arroquia había estudiado. 
la votación (Acta Capitular n³, 19 de enero de 1938. AHMC). No obstante, más allá de eso, su política beneficia principalmente a la oligarquía local, no existiendo planes a largo plazo para paliar la situación económica de la ciudad ni para reanimar la economía. Si bien es cierto que hay medidas que ayudan a los más necesitados, estas no buscan un cambio estructural que acabe con la miseria de estos, sino que tienen un marcado carácter asistencialista, donde prima la ayuda puntual en forma de caridad.

\section{Consideraciones finales}

Tanto Manuel de la Pinta Leal como Juan de Dios Molina Arroquia son representantes de la clase media, personas eficientes en sus trabajos que disfrutaron de una educación con cierto aire liberal. Lejos de ser "hombres del partido", gozan de fama de poseer una buena formación y haber progresado en sus carreras profesionales por méritos propios. Y sin embargo, proviniendo de ambientes en apariencia tan similares, toman caminos totalmente opuestos.

De la Pinta participa apasionadamente en la vida política durante los años democráticos, pero también intenta aplicar a su propia vida los valores que defiende, incluso cuando eso le significa perjuicio económico o enfrentamientos con su familia. Por su parte, Molina no muestra especial interés por la política, e incluso durante su tiempo al frente del ayuntamiento su papel es más el de un técnico que soluciona problemas concretos que van surgiendo que el de un político que afronte cambios estructurales, que en cualquier caso la oligarquía no habría aceptado.

De la Pinta cuenta con escasos recursos, pero sus políticas benefician a las clases obreras, ya sea presionando para que se mejore la habitabilidad de las viviendas en alquiler, ya sea reclamando al gobierno central expropiaciones que favorezcan los intereses de las clases trabajadoras, como en el caso de las instalaciones del seminario o de los astilleros. Molina no cuenta con una situación económica mucho mejor, lo que explica la venta de los terrenos municipales y el programa de obras públicas, que le permite comenzar la urbanización de extramuros y acometer diversos programas de obras públicas, si bien las principales beneficiarias de sus políticas son las élites económicas, que aprovechan la coyuntura para comprar terrenos baratos con los que especular en el futuro.

Ciertamente, la actuación de los alcaldes no podría haber cambiado la situación de Cádiz por sí misma: la crisis económica a la que luego se suma la Guerra Civil son contextos globales contra los que las herramientas legales y económicas de un ayuntamiento poco pueden hacer. No obstante, en la actuación de uno y otro alcalde vemos de fondo la existencia de dos clases 
sociales en conflicto, una clase trabajadora que pone en el gobierno republicano sus esperanzas de mejorar sus condiciones de vida, y una oligarquía económica que no solo se siente dañada por la crisis económica, sino que considera con razón que las actuaciones del gobierno republicano no favorecen sus intereses.

Aunque este estudio se centra solamente en la ciudad de Cádiz en los años treinta, sería interesante y necesario, comparar si esta situación se dio en otras capitales de provincia españolas durante estos años, y si acaso también fue común que el poder municipal gobernase teniendo en mente las necesidades de las clases populares bajo el régimen republicano y las de la oligarquía económica bajo el régimen dictatorial. De igual modo, sería interesante ver quiénes fueron quienes gobernaron, si acaso eran "hombres nuevos" como en el caso de De la Pinta y Molina, o si provenían de los partidos políticos de la monarquía. Finalmente, creemos que este tipo de estudios puede vincularse con otros similares que se desarrollen en otros países, para comprobar si las dinámicas vistas en el caso gaditano y español tienen bases similares a las que tuvieron otras repúblicas a las que sucedieron dictaduras, como en el caso chileno (1973-1990), argentino (1976-1983) o portugués (1926-1974).

\section{Referencias bibliográficas}

\section{Fuentes Primarias}

\section{a. Documentales}

Archivo General de la Universidad Politécnica de Madrid (AGUPM)

Archivo Histórico de Aguas de Cádiz S.A. (AHAC)

Archivo Histórico de la Familia Molina (AHFM)

Archivo Histórico Municipal de Cádiz (AHMC)

Archivo Militar General de Segovia (AGMS)

Archivo del Ministerio de Hacienda (AMH)

Archivo de la Universidad de Cádiz (AUCA)

\section{b. Impresos}

DIRECCIÓN GENERAL DE ESTADÍSTICA (1943). Censo de la población de España a 31 de diciembre de 1940. Madrid, España: Ministerio de Trabajo. 
INSTITUTO GEOGRÁFICO, CATASTRAL Y DE ESTADÍSTICA (1932). Censo de la población de España a 31 de diciembre de 1930. Madrid, España: Presidencia del Consejo de Ministros.

INSTITUTO NACIONAL DE ESTADÍSTICA (1957). Reseña estadística de la Población de Cádiz. Madrid, España: Presidencia del Gobierno.

\section{c. Publicaciones periódicas}

DIARIO ACCIÓN REPUBLICANA

DIARIO DE CÁDIZ

DIARIO LA INFORMACIÓN

REVISTA ÁGUILA

\section{Fuentes secundarias}

BACKSCHEIDER, P.R. (1999). Reflections on Biography. Oxford, Reino Unido: Oxford University Press.

BARRUSO BARÉS, P. (Ed.). (2010). Diccionario biográfico del socialismo español (1879-1939). Madrid, España: Fundación Pablo Iglesias.

BENÍTEZ ARAGÓN, R.; S. Moreno Tello y J. Núñez Calvo (2011). "Manuel De la Pinta Leal, último alcalde de la Segunda República en Cádiz", en S. Moreno Tello (Ed.), La destrucción de la Democracia: Vida y muerte de los alcaldes del Frente Popular en la provincia de Cádiz, vol.1. Sevilla, España: Consejería de Delegación y Justicia de la Junta de Andalucía. p. 341-384.

BUSTOS RODRÍGUEZ, M. (2005). Cádiz en el sistema atlántico: La ciudad, sus comerciantes y su actividad mercantil (1650-1830). Madrid, España: Sílex.

CARO CANCELA, D. (1987). La segunda república en Cádiz: Elecciones y partidos políticos. Cádiz, España: Diputación de Cádiz.

CASANOVA, J. y C. Gil Andrés (2009). Historia de España en el siglo XX. Barcelona, España: Ariel.

DE PABLO, S. (1990). Continuidad y cambio en las élites políticas locales, de la Restauración a la II República: El caso de Álava. Espacio tiempo y forma, Serie V, $H^{a}$ Contemporánea t.3, p. 237-248.

DOMÍNGUEZ PÉREZ, A. (2005). El verano que trajo un largo invierno: La represión político-social durante el primer Franquismo en Cádiz (1936-1945). Cádiz, España: Quórum.

ESPINOZA MAESTRE, F. (2003). La columna de la muerte: el avance del ejército franquista de Sevilla a Badajoz. Barcelona, España: Crítica. 
ESPINOZA MAESTRE, F. (2005). Apuntes para la historia de la sublevación de julio de 1936 en Cádiz. Almajar, 2, p. 177-193.

GUTIÉRREZ MOLINA, J.L. (1994). Crisis burguesa y unidad obrera. El sindicalismo en Cádiz durante la Segunda República. Madrid, España: Madre Tierra.

GUTIÉRREZ MOLINA, J.L. (1996). Capital vasco e industria andaluza: El astillero de Echevarrieta y Larrinaga de Cádiz (1917-1952). Cádiz, España: Servicio de Publicaciones de la Universidad de Cádiz.

LÓPEZ AGUILAR, J.F. (Ed.). (2013). Juan Negrín López (1892-1956). Madrid, España: Servicio de Publicaciones del Congreso de los Diputados.

MARTínEZ VARGAS, A. (1996). El agua y la electricidad en Cádiz, Historia de los SMAES. Cádiz, España: Artes Gráfica Nuevas.

MESA FERNÁNDEZ, N. (1996). Historia de Jódar. Jaén, España: Asociación Cultural Saudar.

MILLÁN CHIVITE, J.L. (1993). Cádiz en el siglo XX: Del Cádiz hundido al Cádiz que resurge (1898-1979). Madrid, España: Sílex.

MIRÁS ARAUJO, J. (2004). "La estructura profesional de una ciudad terciaria: A Coruña, 1900-1960", en Revista electrónica Scripta Nova, Vol. VIII, n 163. Puede consultarse online en http://www.ub.edu/geocrit/sn/sn-163.htm

MORA FIGUEROA, J. (1974). Datos para la historia de la falange gaditana, 19341939. Jerez de la Frontera, España: Gráficas del exportador.

MORAL RONCAL, A.M. (2012). Anticlericalismo y poder: la desacralización de las calles y los espacios públicos durante la Segunda República. Hispania Sacra LXIV (Extra I), p. 47-68.

MORENO TELLO, S. (2006). La clase obrera gaditana (1949-1959): Una historia social a través de las fuentes populares. Cádiz, España: Servicio de Publicaciones de la Universidad de Cádiz.

MORENO TELLO, S. (2008). Periodistas represaliados en Cádiz. Cádiz, España: Asociación de la Prensa de Cádiz.

PETTENGHI LACHAMBRE, J.A. (2005). La escuela derrotada. Cádiz, España: Quórum Editores.

PIÑEIRO BLANCA, J. (1998). Ramón de Carranza: un oligarca gaditano en la crisis de la Restauración, Cádiz, España: Servicios de Publicaciones de la Universidad de Cádiz y la Diputación de Cádiz.

PRESTON, P. (2011). El holocausto español: Odio y exterminio en la Guerra Civil española. Barcelona, España: Debate. 
RAMOS SANTANA, A. (1992). Cádiz en el siglo XIX: De ciudad soberana a capital de provincia. Madrid, España: Sílex.

RAVINA RIPOLL, R. (2007). "Juan de Dios Molina: Breve acercamiento al primer alcalde franquista", en Revista Ubi Sunt?, 21, p. 2-8.

RAVINA RIPOLL, R. (2010). "Juan de Dios Molina Arroquia: Un alcalde de Cádiz en la Colina de los Chopos de Madrid", en Hades, 8, p. 8-9.

RODRÍGUEZ MORENO, J. J. (2013). "El Temerario: Un ejemplo del reflejo de la sociedad española de posguerra en las viñetas", en Revista Historietas, 3, p. 83-108.

ROMERO ROMERO, F. (2009). "Represión y muerte en la provincia de Cádiz: Del olvido a la recuperación de la Memoria Histórica", en S. Moreno Tello y J.J. Rodríguez Moreno (Eds.), Marginados, disidentes y olvidados en la Historia. Cádiz, España: Servicio de Publicaciones de la Universidad de Cádiz, p. 285-322.

ROMERO ROMERO, F. (2011). "Fernando Zamacola: un héroe gaditano de la Guerra Civil", en A. Martínez García, A. Quintana Fernández y V. Sibón Rodríguez (Eds.), Héroes y villanos en la Historia. Cádiz, España: Asociación Ubi Sunt? y Centro de Profesores de Jerez de la Frontera (Consejería de Educación, Junta de Andalucía), p. 203-222.

RUIZ MANJÓN-CABEZA, O. (1979). "Autoridades locales y partidos políticos en Andalucía durante la Segunda República", en Revista Española de Investigaciones Sociológicas, № 5, p. 167-181.

SÁENZ DE LA CALZADA, M. (1986). La residencia de estudiantes (1910-1936). Madrid, España: Consejo Superior de Investigaciones Científicas.

SAINZ OTERO, A. M. (2007). La mortalidad en Cádiz (1923-1939). Tesis Doctoral: Universidad de Cádiz, España.

SEVILLA ANDRÉS, D. (2010). Antonio Maura: La revolución desde arriba. Madrid, España: Servicio de Publicaciones del Congreso de los Diputados.

URQUIJO GOITÍA, J. (Ed.). (2010). Diccionario Biográfico de Parlamentarios Españoles. Madrid, España: Servicio de Publicaciones del Congreso de los Diputados.

VILAR, P. (1986). La Guerra Civil española. Barcelona, España: Crítica.

WALTER, J. (2006). "The Utility of Short Lives", en Biography, 29 (2), p. 329-337. 